\title{
THE EFFECT OF FUNCTIONAL LIMITATIONS AND FATIGUE ON THE QUALITY OF LIFE IN PEOPLE WITH MULTIPLE SCLEROSIS
}

\author{
Leandro Alberto Calazans Nogueira', Felipe Resende Nóbrega $a^{2}$, Kátia Nogueira Lopes', \\ Luiz Claudio Santos Thuler ${ }^{4}$, Regina Maria Papais Alvarenga ${ }^{5}$
}

\begin{abstract}
The purpose of this study was to determine the effect of functional limitations and fatigue on the quality of life (QoL) in people with multiple sclerosis (MS). A descriptive case series study at Lagoa Hospital Rio de Janeiro, Brazil was carried. The main outcome measurements were demographic variables, QoL (SF-36 v.1), disability (EDSS), motor function of the upper limb (Box \& Blocks test), Tone (Modified Ashworth Scale), gait (Hauser ambulatory index) and fatigue (Fatigue Severity Scale). Sixty one patients fulfilled the study criteria. The mean age of patients was 39 years and $74 \%$ of patients were female. The most of cases presented mild disability (EDSS $\leq 3.5$ ). A decrease was found in all domains of QoL. It was found association between physical functioning and the variables of EDSS, fatigue, lower limb tone and gait. Gait, disability, hypertonia of the lower limbs and fatigue negatively affected QoL in people with MS.
\end{abstract}

KEY WORDS: multiple sclerosis, quality of life, physically disable, gait.

\begin{abstract}
O efeito das limitações funcionais e da fadiga na qualidade de vida de indivíduos com esclerose múltipla
Resumo - O objetivo do estudo foi determinar o efeito das limitações funcionais e da fadiga na qualidade de vida (qv) de indivíduos com esclerose múltipla (em). foi conduzido um estudo descritivo de série de casos no Hospital da Lagoa - Rio de Janeiro, Brasil. As principais medidas utilizadas foram as variáveis demográficas, QV (SF-36 v.1), incapacidade (EDSS), função motora da extremidade superior (Teste da Caixa e Blocos), Tônus (Escala Modificada de Ashworth), marcha (Índice Ambulatorial de Hauser) e fadiga (Escala de Severidade de Fadiga). Sessenta e um pacientes preencheram os critérios do estudo. A média de idade foi de 39 anos e $74 \%$ dos pacientes eram do gênero feminino. A maioria dos casos apresentou incapacidade leve (EDSS $\leq 3,5)$. Foi encontrada uma diminuição em todas dimensões da QV. Foi observada uma associação entre a função física e as variáveis EDSS, fadiga, tônus dos membros inferiores e marcha. Marcha, incapacidade, hipertonia dos membros inferiores e fadiga afetam negativamente a QV de indivíduos com EM.
\end{abstract}

PALAVRAS-CHAVE: esclerose múltipla, qualidade de vida, incapacidade física, marcha.

Multiple sclerosis (MS) is a demyelinating disease that affects the central nervous system. The disease generally affects young adults in the productive phase of their professional life and is considered an incapacitating disease ${ }^{1}$. Patients with MS are frequently affected by abnormalities in gait and motor signs that affect their quality of life (QoL)2. Various authors have clearly shown a de- crease in the QoL of patients with MS compared to control groups ${ }^{3,4}$. The SF-36 scale has been widely used in QoL studies carried out in MS patients ${ }^{2,5-10}$.

Among the factors that affect the QoL of the individual with MS are fatigue ${ }^{6,11}$, depression ${ }^{7,11,12}$, anxiety ${ }^{12}$, impaired physical and cognitive function, and disease progression². Fatigue, disability and decreased sleep quality

\footnotetext{
'Physiotherapist, MSc of Gaffrée e Guinle Universitary Hospital; Neurology Department - UNIRIO; Physical Therapy Department of Gama Filho University, Rio de Janeiro RJ, Brazil; ${ }^{2}$ Physiotherapist, MSc of Gaffrée e Guinle Universitary Hospital; Physical Therapy Department of Celso Lisboa University, Rio de Janeiro RJ, Brazil; ${ }^{3}$ Physiotherapist, MSc of Gaffrée e Guinle Universitary Hospital; Neurology Department - UNIRIO, Rio de Janeiro RJ, Brazil; ${ }^{4} \mathrm{PhD}$, Neurology Department - UNIRIO, Rio de Janeiro RJ, Brazil, Neurology Graduation Program Professor - UNIRIO, Rio de Janeiro RJ, Brazil; ${ }^{5}$ PhD, Neurology Department - UNIRIO, Neurology Graduation Program Coordinator - UNIRIO, Rio de Janeiro RJ, Brazil.
}

Received 17 April 2009, received in final form 13 July 2009. Accepted 11 August 2009.

Dr. Leandro Alberto Calazans Nogueira - Hospital Universitário Gaffrée e Guinle / Departamento de Neurologia - Rua Mariz e Barros 775 - $20270-004$ Rio de Janeiro RJ - Brasil. E-mail: Icalazansnogueira@gmail.com 
have a negative effect on the physical appearance of the patient ${ }^{11}$. Using the SF-36, Forbes et al..$^{13}$ found that fatigue, pain, depression and employability all have a negative effect on QoL. In $90 \%$ of the patients in Brazil, the clinical course of MS is relapsing-remitting (RR). In a cohort of 467 MSRR patients, following a mean duration of the disease of 7.5 years, functional systems were affected in the following proportions: pyramidal $61 \%$, cerebellar $26 \%$, brainstem $18 \%$, sensorial $40 \%$, bowel and bladder $29 \%$, visual $27 \%$ and mental $14 \%{ }^{14}$.

Bearing in mind the high prevalence of the relapsingremitting form of MS and the high rate at which the pyramidal motor system is affected, this study was carried out to evaluate the effect of functional limitations and fatigue on the QoL in people with MS.

\section{METHOD}

\section{Data collection procedures}

A descriptive, observational study was carried out at the Hospital da Lagoa in the city of Rio de Janeiro, Brazil between March and June 2006 in a convenience sample that included all the patients with MS who were seen during that period. The variables evaluated were: age, gender, time of the disease in years, education level, monthly income, profession, dominant limb, quality of life, gait, upper and lower limb tone, fatigue and upper limb function. All participants signed an informed consent form prior to admission to the study. The study was approved by the Internal Review Board of the Gaffree and Guinle Teaching Hospital, and the recommendations of the National Counsel of Ethics in Research (CONEP) were strictly adhered to throughout the trial.

\section{Characteristics of the study sample}

Inclusion criteria consisted of: a diagnosis of MS according to the criteria established by McDonald et al..$^{15}$ and confirmation that the patient had the relapsing-remitting form of $\mathrm{MS}^{16}$. Exclusion criteria comprised: patients with other forms of idiopathic demyelinating disease, patients currently undergoing an MS attack, and patients with another associated neurological disease or with impaired cognitive function preventing him/her from completing the scales. A total of 61 patients who met all the inclusion criteria were evaluated in this study.

\section{Main outcome measures}

The instruments used in the evaluation were: the Medical Outcome Study Short Form-36, version 1 (SF-36 v1) consisting of 36 closed questions divided into 8 domains, which served as a measure of health-related quality of $\mathrm{life}^{17}$. The questionnaire was validated for use in the Portuguese language by Ciconelli et al. ${ }^{18}$.

Evaluation of the Expanded Disability Status Scale (EDSS) was performed by a team of physicians trained in its quantification. The physiotherapist was blinded to the results.

The Box and Block Test evaluates manual dexterity for the assessment of upper limb function. The test consists of a box of $53.7 \mathrm{~cm}$ in length with a dividing partition extending above the edges of the box, separating it into two equal-sized compartments. The 150 blocks each measure $2.5 \times 2.5 \times 2.5 \mathrm{~cm}$. The individual is instructed to transfer as many blocks as possible from one compartment of the box to the other within a period of 60 seconds. The test should be carried out using one hand at a time. The standard score is 60 blocks $^{19}$.

The Fatigue Severity Scale is a self-applicable questionnaire composed of 9 statements regarding the presence of fatigue over the past two weeks. For each statement, the patient being examined is instructed to give a grade ranging from 1 to 7,7 corresponding to maximum agreement. The total score ranges from 9 to 63 , a score $\geq 28$ being considered as indicative of the presence of fatigue ${ }^{20}$.

The Modified Ashworth Scale of Spasticity evaluates the resistance felt to passive movement. The scale is classified as: 0 , $1,1+, 2,3$ or 4,4 representing greater hypertonia. Scores of 0,1 and $1+$ were considered clinically insignificant ${ }^{21}$.

The Hauser Ambulatory Index evaluates gait. This index was used to assess the time and effort used by the patient to walk 25 feet ( 8 meters). The scale ranges from 0 to 9,0 being the best score ${ }^{22}$.

\section{Data analysis}

Data analysis was carried out using the following software programs: Epilnfo, version 3.3.2, and SPSS, version 12 for Windows. The results are presented as proportions, measures of central trends such as means, medians and standard deviations, and measures of association such as the odds ratio (OR) with its respective $95 \%$ confidence intervals $(95 \% \mathrm{Cl})$. Spearman's rank correlation was performed for all the variables analyzed. Values between 0 and 0.19 were classified as very weak correlation, 0.20 to 0.39 weak correlation, 0.40 to 0.59 moderate correlation, 0.60 to 0.79 strong correlation, while 0.80 to 1 were scores indicative of very strong correlation. The statistical significance of the differences observed between the dichotomous variables was analyzed using the chi-squared test or Fisher's exact test, as appropriate. Significance level was established at $5 \%(p<0.05)$.

Quality of life scores were analyzed using the QualityMetric software program ${ }^{17}$.

To calculate the $O R$, the variables of age and duration of the disease were dichotomized according to median values. QoL was dichotomized into scores $<50$ or $\geq 50$ in accordance with the recommendations of the SF- 36 manual, QoL scores $<50$ being considered as an indication that QoL was affected. EDSS was dichotomized into mild ( $\leq 3.5)$ or moderate/severe ( $>3.5)$. With respect to upper limb function, the cut-off point was 60 blocks, values below 60 being classified as abnormal. With respect to fatigue, scores $\geq 28$ were considered indicative of the presence of this symptom as Lebre et al. ${ }^{23}$ study. Tone was classified as clinically increased when scores were $\geq 2$, while gait was considered not to be significantly affected when scores were between 0 and 3 . 
The degree of disability was classified according to the definitions established by Pfennings et al. ${ }^{5}$, who considered an EDSS score of 0-3.5 as mild, 4.0-6.5 as moderate and 7-10 as severe.

\section{RESULTS}

The mean age of patients in this study was 39 years $(S D \pm 11.06)$ and $74 \%$ of patients were female. The mean duration of the disease from diagnosis until this evaluation was 8.4 years. With respect to education level, $48 \%$ of patients had completed secondary school, while $41 \%$ had graduated from university. The demographic data of the patients are summarized in Table 1. With respect to functional abnormalities, the majority of patients had mild disability (EDSS $\leq 3.5$ ) and 22 patients (36\%) had a score of 0 in the evaluation of motor function. In fifteen patients (24.6\%), evolution of the disease was considered benign, as defined by $>10$ years of duration of the disease and EDSS $\leq 3$.

A decrease was found in all domains of QoL. In the physical and mental components, the mean was below the reference values (41.84 and 40.05, respectively). The most affected domain was that of physical functioning followed by the role limitations - physical, whereas the least affected was general health. The mean values and standard deviations of all the domains are shown in Table 2 and the values of the quartiles, medians and upper and lower limits are shown in Figure.

After classification of physical functioning in the QoL evaluation into good (score $\geq 50$ ) or poor $(<50)$ in accordance with the reference values ${ }^{17}$, the associations of this domain, which was the domain that was most affected, were tested with the different scales of functional limitations, with fatigue and with the demographic data. The results are described in Table 3 and listed in accordance with significance level. Statistically significant values were found for the association of physical functioning with the variables of EDSS (OR=10.11; 95\% CI [1.85-72.76]; $\mathrm{p}<0.01$ ), fatigue (OR=4.83; 95\% Cl [1.32-18.52]; $\mathrm{p}<0.01)$, lower limb tone (OR=4.20; 95\% Cl [1.05-17.71]; $\mathrm{p}=0.02)$ and gait (OR=4.53; 95\% Cl [1.00-23.36]; $\mathrm{p}=0.02$ ).

In the analysis of correlation, moderate correlation was found between physical functioning in the QoL assessment and evaluation of vision, gait and fatigue. The other statistically significant correlations, albeit considered weak, are shown in Table 4 and listed in accordance with the strength of the correlations.

\section{DISCUSSION}

The demographic analysis of this series shows that individuals with MS in Rio de Janeiro have demographic characteristics similar to those described in other regions of $\mathrm{Brazil}^{23-27}$ and in the rest of the world ${ }^{2,7,8,10,28,29}$. From a clinical perspective, the value of EDSS measured after a mean duration of 8.4 years of the disease indicated mild
Table 1. Demographic data of MS patients in Brazil ( $n=61)$.

\begin{tabular}{|c|c|c|}
\hline & $\begin{array}{c}\text { Number } \\
(\%)\end{array}$ & $\begin{array}{c}\text { Average } \\
( \pm S D)\end{array}$ \\
\hline Age (years) & & $39( \pm 11.1)$ \\
\hline Above 40 & $30(49.2)$ & \\
\hline Under 40 & $31(50.8)$ & \\
\hline \multicolumn{3}{|l|}{ Gender } \\
\hline Female & $45(73.8)$ & \\
\hline Male & $16(26.2)$ & \\
\hline Duration of illness (years) & & $8.38( \pm 7.0)$ \\
\hline Above 7 & $30(49.2)$ & \\
\hline Under 7 & $31(50.8)$ & \\
\hline \multicolumn{3}{|l|}{ Education } \\
\hline Elementary school & $4(6.4)$ & \\
\hline High School & $29(47.5)$ & \\
\hline Graduated and above degree & $25(41.0)$ & \\
\hline Monthy income (USD) & & $\$ 473,12$ \\
\hline Above $\$ 298,08$ & $30(49.2)$ & \\
\hline Under $\$ 298,08$ & $31(50.8)$ & \\
\hline \multicolumn{3}{|l|}{ Dominant limb } \\
\hline Right & $56(91.8)$ & \\
\hline Left & $5(8.2)$ & \\
\hline EDSS & & $2.8( \pm 2.0)$ \\
\hline Mild & $43(70.5)$ & \\
\hline Moderate & $15(24.6)$ & \\
\hline Severe & $3(4.9)$ & \\
\hline
\end{tabular}

Table 2. Values found on the QoL evaluation measured through SF-36 questionnaire in $61 \mathrm{MS}$ patients in Brazil.

\begin{tabular}{lcc}
\hline $\begin{array}{l}\text { Quality of life } \\
\text { (Dimensions) }\end{array}$ & $\begin{array}{c}\text { Average (SD) } \\
\text { Values 0-100 }\end{array}$ & $\begin{array}{c}\text { Average (SD) } \\
\text { Norm based sored 50 }\end{array}$ \\
\hline Physical component & & $41.84( \pm 11.03)$ \\
Mental component & & $40.05( \pm 11.55)$ \\
Physical function & $48.15( \pm 31.33)$ & $35.39( \pm 13.14)$ \\
Role physical & $28.23( \pm 38.54)$ & $35.94( \pm 10.9)$ \\
Bodily pain & $61.61( \pm 32.54)$ & $46.31( \pm 14)$ \\
General health & $63.29( \pm 23.86)$ & $46.81( \pm 11.17)$ \\
Vitality & $48.39( \pm 25.2)$ & $45.92( \pm 11.93)$ \\
Social function & $54.23( \pm 30.28)$ & $37.26( \pm 13.15)$ \\
Role emotional & $38.71( \pm 37.79)$ & $35.97( \pm 11.94)$ \\
Mental health & $57.18( \pm 24.13)$ & $39.75( \pm 13.71)$ \\
\hline
\end{tabular}

On the second column the values found from 0-100 and on third column norm based scored to 50 .

disability in the majority of cases like Ferreira et al. ${ }^{25}$. Similar findings have been described in studies on QoL carried out in Germany by Merkelbach, Sittinger and Koenig ${ }^{6}$, in Holland by Janssens et al. ${ }^{8}$, in the United States by Pittock et al. ${ }^{9}$ and in Brazil by Morales et al. ${ }^{26}$. 


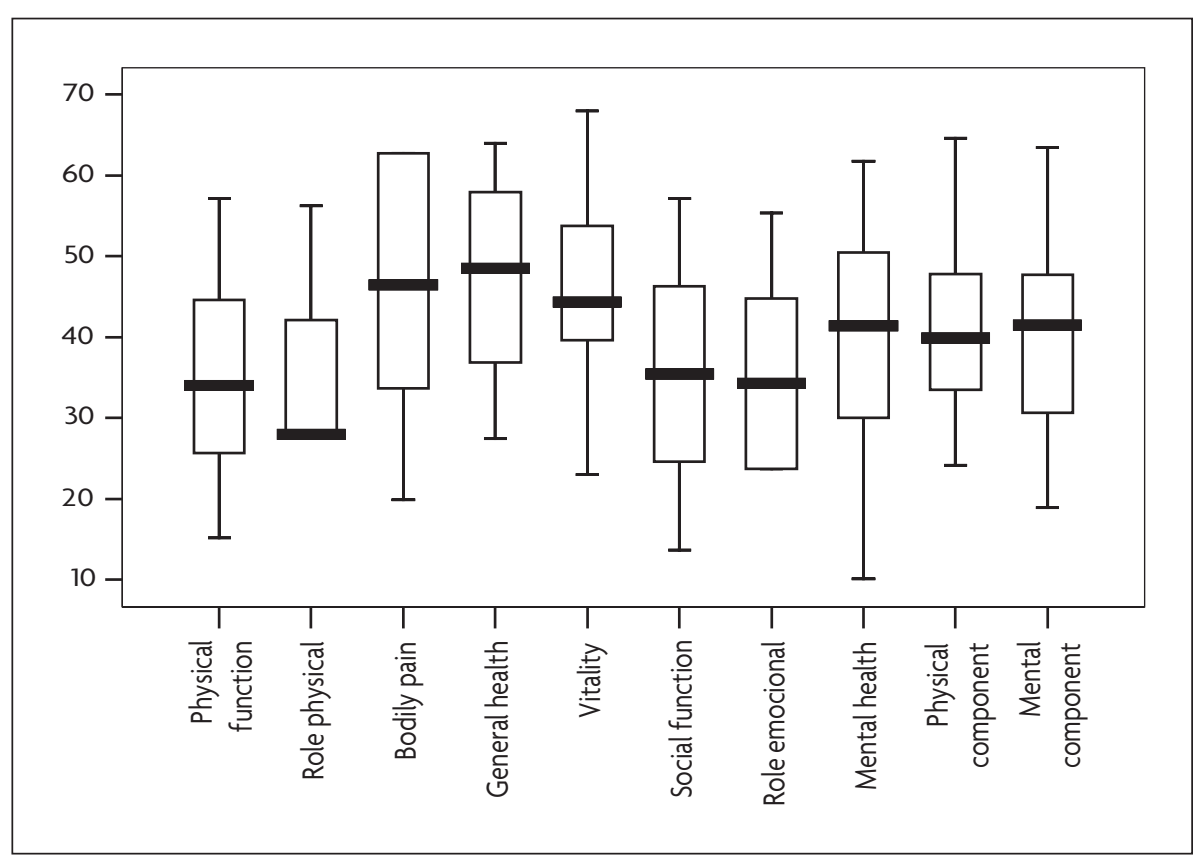

Figure. QoL dimensions in 61 MS patients in Brazil.

Table 3. Association measures among the QoL physical function dimension and the motor functions, fatigue and demographic data in 61 MS patients in Brazil.

\begin{tabular}{|c|c|c|c|c|}
\hline & \multicolumn{2}{|c|}{ Physical function } & \multirow[t]{2}{*}{ OR $(95 \% \mathrm{Cl})$} & \multirow[t]{2}{*}{$p$ value } \\
\hline & Poor & Good & & \\
\hline \multicolumn{5}{|l|}{ EDSS* } \\
\hline Moderate and severe $(>3.5)$ & 16 & 2 & $10.11(1.85-72.76)$ & $<0.01^{* *}$ \\
\hline Mild ( $\leq 3.5)$ & 19 & 24 & & \\
\hline \multicolumn{5}{|l|}{ Fatigue } \\
\hline With fatigue & 29 & 13 & $4.83(1.32-18.52)$ & $<0.01^{* *}$ \\
\hline Without fatigue & 6 & 13 & & \\
\hline \multicolumn{5}{|l|}{ Lower Limb Tone } \\
\hline Clinically higher & 13 & 5 & 4.20 (1.05-17.71) & $0.02 * *$ \\
\hline Clinically normal & 13 & 21 & & \\
\hline \multicolumn{5}{|l|}{ Hauser ambulatory index } \\
\hline Important alteration & 13 & 3 & $4.53(1.00-23.36)$ & $0.02^{\star *}$ \\
\hline No alteration & 22 & 23 & & \\
\hline \multicolumn{5}{|l|}{ Motor functional system } \\
\hline Different from 0 & 26 & 13 & $2.89(0.86-9.86)$ & 0.05 \\
\hline Equal to 0 & 9 & 13 & & \\
\hline \multicolumn{5}{|l|}{ Age } \\
\hline$>40$ years & 21 & 10 & $2.40(0.75-7.79)$ & 0.09 \\
\hline$\leq 40$ years & 14 & 16 & & \\
\hline \multicolumn{5}{|l|}{ Duration of illness } \\
\hline$>7$ years & 13 & 11 & $0.81(0.25-2.58)$ & 0.68 \\
\hline$\leq 7$ years & 22 & 15 & & \\
\hline \multicolumn{5}{|l|}{ Gender } \\
\hline Female & 27 & 18 & $1.50(0.41-5.48)$ & 0.49 \\
\hline Male & 8 & 8 & & \\
\hline
\end{tabular}

The variables were presented according to significance level; *EDSS: Expanded Disability Status Scale; **Statistical significance. 
Table 4. Spearman's correlation values among the QoL, demographic data, fatigue and motor functions in $61 \mathrm{MS}$ patients in Brazil.

\begin{tabular}{lc}
\hline QoL Dimensions & Spearman's correlation ( $p$ value) \\
\hline Physical function $\times$ Visual FS & $-0.53(<0.01)$ \\
Physical function $\times$ Hauser ambulatory index & $-0.51(<0.01)$ \\
Physical function $\times$ Fatigue & $-0.42(<0.01)$ \\
Physical function $\times$ EDSS & $-0.39(<0.01)$ \\
Physical function $\times$ Motor FS & $-0.38(<0.01)$ \\
Physical function $\times$ Upper limb function & $0.26(0.04)$ \\
\hline
\end{tabular}

The table is arranged according to the correlation magnitude.

In all patients evaluated in this study, the onset of the disease was in the relapsing-remitting form and only 9 $(15 \%)$ had secondary progression, less than reported by Ferreira et al..$^{25}(23.7 \%)$. The benign form of the disease was identified in $20 \%$ of cases. No correlation was found between duration of the disease and QoL as Morales et al. ${ }^{26}$ reported previously. A study comparing the different forms of evolution of MS found that the more chronic and progressive the course of the disease, the lower the values found in the SF-36 scale ${ }^{6}$. Other studies have confirmed this observation ${ }^{5,728}$; however, this finding may be attributable to the form of evolution and not necessarily to the duration of the disease.

General health was the least affected domain, with scores approaching the cut-off point. No correlation was established between the vitality domain and any of the variables evaluated. Mean duration of the disease $<10$ years and the mild disability found in around two-thirds of cases justifies this result. Studies carried out by Janssens et al. ${ }^{8}$ and Delgado-Mendilivar et al. ${ }^{2}$ reported a decrease in the general health and vitality domains in series of patients who also had mild disability.

The results of this study confirm that fatigue, increased lower limb tone, poor gait and greater disability are independent factors that negatively affect the QoL in people with MS.

The rate of $69 \%$ of fatigue among patients with MS in Rio de Janeiro is in agreement with data reported in the scientific literature, which ranges from 50 to $96 \%{ }^{23,29}$. These results show that fatigue is an important factor to be considered in the treatment of the patient with MS. Miller et al. ${ }^{27}$ found no difference between the degree of severity of fatigue and the classification of disability. Individuals with MS refer to the presence of fatigue regardless of the stage and duration of the disease. This symptom is associated with the symphathetic nervous system dysfunction ${ }^{23}$. Pittion-Vouyovitch et al. ${ }^{29}$ reported a high correlation between fatigue and a decrease in all the QoL domains in 237 patients with MS and mild or moderate disability (EDSS $<7)$. Merkelbach, Sittinger and Koenig ${ }^{6}$ report- ed a correlation between fatigue and lower scores in the Physical and Mental Components of QoL, which is also in agreement with the results reported here.

Physical functioning was the most affected domain among the patients of the present study as the Morales et al. ${ }^{26}$ study. Visual disability was the variable most strongly correlated with this domain followed by gait and fatigue. This result is in agreement with the findings of DelgadoMendilivar et al. ${ }^{2}$, who reported a large percentage of patients in whom vision and gait were affected and who had low scores in the Physical Functioning domain.

A negative correlation was found between disability and the physical functioning domain in the SF-36 scale, i.e. the more severe the disability, the greater the extent to which the Physical Functioning domain was affected. The scoring system of the Kurtzke EDSS scale considers gait to be impaired when the score is $\geq 4$. Progression of the disease affects independent gait, a characteristic of the evolution of MS. Patti et al.' and Merkelbach, Sittinger and Koenig ${ }^{6}$ reported a correlation between disability and all the SF-36 domains with the exception of mental health. They also found a greater correlation with the physical functioning domain in agreement with the findings of the present study and with those presented by Pittock et al..

Despite the strong correlation between physical functioning and disability, the correlations between the EDSS scores and the QoL scores found for the other domains were very weak or failed to show statistical significance. Patti et al. ${ }^{7}$ suggested that the EDSS may not constitute a valid instrument for the detection of changes in the QoL of MS patients.

Upper limb function was not associated or correlated with QoL. Clinically increased muscle tone in the lower limbs was associated with a reduction in QoL in the physical functioning domain. Spastic hypertonia is one of the neurological signs of pyramidal syndrome, the most common manifestation of MS.

QoL in MS is related to physical aspects, which are reflected in functional and/or social limitations. In the rehabilitation of patients, physical management is essential for 
an improvement in QoL. Treatment protocols should give emphasis to lower limb function, particularly gait training. Treatment of fatigue, the only variable studied that negatively affected both the physical and mental components of the SF-36 scale, is equally important and directly related. Studies involving physical activity to improve the QoL of patients with MS have been carried out with good results ${ }^{7,30}$.

\section{Study limitations}

Few studies use the norm-based score recommended in the SF-36 manual ${ }^{17}$; therefore, comparison of the statistical analysis of the odds ratios was limited to the study carried out by Pittock et al... Other investigators have used percentage descriptions, limiting comparisons of the results of this study to those observed in other series.

Another possible limitation of the study was the difficulty in determining the duration of the disease, since the initial symptoms are variable and often regress spontaneously, which probably hinders diagnosis.

Since analyzing depression and employability was not within the objectives of this study, the effect of these variables on QoL was not evaluated. Patti et al. ${ }^{7}$, Morales et al. ${ }^{26}$ and Miller and Dishon ${ }^{10}$ have already shown the effect of these factors on the QoL of MS patients.

In MS patients, a decrease in QoL was found in all domains, principally in the physical functioning and role limitations - physical, the domains in which the lowest scores were found. Gait, disability, hypertonia of the lower limbs and fatigue negatively affected QoL. Fatigue was the only variable evaluated that negatively affected both the physical and the mental components of the QoL irrespective of the duration of the disease or the degree of disability. Treatments that give emphasis to physical functioning, gait and fatigue should be considered in order to improve the QoL in people with MS.

\section{REFERENCES}

1. Poser CM, Paty DW, Scheinberg L et al. New diagnostic criteria for multiple sclerosis: guideline for research protocols. Ann Neurol 1983;13:227-233.

2. Delgado-Mendilívar JM, Cadenas-Diaz JC, Fernandez-Torrico JM, Navarro-Mascarell G, Izquierdo G. Estudio de la calidad de vida en la esclerosis múltiple. Rev Neurol 2005;41:257-262.

3. Nortvedt MW, Riise T, Myhr KM, Nyland HI. Quality of life in multiple sclerosis: measuring the disease effects more broadly. Neurology 1999;53:1098-1103.

4. McCabe MP, Mckern S. Quality of life and multiple sclerosis: comparison between people with multiple sclerosis and people from the general population. J Clin Psychol Med Settings 2002;9:287-295.

5. Pfennings L, Cohen L, Ader H, et al. Exploring differences between subgroups of multiple sclerosis patients in health-related quality of life. J Neurol 1999;246:587-591.

6. Merkelbach, Sittinger, Koenig. Is there a differential impact of fatigue and physical disability on quality of life in multiple sclerosis? J Nerv Ment Dis 2002;190:388-393.

7. Patti F, Cacopardo M, Palermo F, et al. Health-related quality of life and depression in an Italian sample of multiple sclerosis patients. J Neurol Sci 2003;211:55-62.
8. Janssens AC, van Doom PA, de Boer JB, van der Meche FG, Passchier J, Hintzen RQ. Impact of recently diagnosed multiple sclerosis on quality of life, anxiety, depression and distress of patients and partners. Acta Neurol Scand 2003;108:389-395.

9. Pittock SJ, Mayr WT, McClelland RL, et al. Quality of life is favorable for most patients with multiple sclerosis. Arch Neurol 2004;61:679-686.

10. Miller A, Dishon S. Health-related quality of life in multiple sclerosis: the impact of disability, gender and employment status. Qual of Life Res 2006;15:259-271.

11. Lobentanz IS, Asenbaum S, Vass K, et al. Factors influencing quality of life in multiple sclerosis patients: disability, depressive mood, fatigue and sleep quality. Acta Neurol Scand 2004;110;6-13.

12. Fruehwald S, Loeffler-Stastka H, Eher R, Saletu B, Baumhackl U. Depression and quality of life in multiple sclerosis. Acta Neurol Scand 2001;104:257-261.

13. Forbes A, While A, Mathes L, Griffiths P. Health problems and healthrelated quality of life in people with multiple sclerosis. Clin Rehabil 2006;20:67-78.

14. Alvarenga RMP. South Atlantic Project: A Brazilian Multiple Sclerosis. In: Esclerosis Multiple. In: Arriagada CR, Nogales Gaete J (Eds). Uma Mirada Ibero-Americana. Santiago, Chile 2002:129-151.

15. McDonald WI, Compston A, Edan G, et al. Recommended diagnostic criteria for multiple sclerosis: guidelines from the International Panel on the diagnosis of multiple sclerosis. Ann Neurol 2001;50:121-127.

16. Lublin FD, Reingold SC. Defining the clinical course of multiple sclerosis: results of an international survey. National Multiple Sclerosis Society (USA) Advisory Committee on Clinical Trials of New Agents in Multiple Sclerosis. Neurology 1996;46:907-911.

17. Ware JE, Kosinski M, Gandek B. SF-36 Health survey: manual e interpretation guide. Lincoln. Quality Metric Inc, 2005:78-82.

18. Ciconelli RM, Ferraz MB, Santos W, Meinao I, Quaresma, MR. Tradução para a língua portuguesa e validação do questionário genérico de avaliação de qualidade de vida SF-36 (Brasil SF-36). Rev Bras Reumatol 1999; 39:143-150.

19. Mathiowetz VG, Volland G, Kashman N, Weber K. Adult norms for the box and block tests of manual dexterity. Am J Occup Ther 1985;39:386-391.

20. Krupp LB, LaRocca NC, Muir-Nash J, Steinberg AD. The fatigue severity scale: application to patients with multiple sclerosis and systemic lupus erythematous. Arch Neurol 1989;46:1121-1123.

21. Bohannon RW, Smith MB. Interrater reliability of a modified Ashworth scale of muscle spasticity. Phys Ther 1987;67:206-207.

22. Hauser SL, Dawson DM, Lehrich JR, et al. Intensive immunosuppression in progressive multiple sclerosis: a randomized, three-arm study of high-dose intravenous cyclophosphamide, plasma exchange, and ACTH. N Engl J Med 1983;308:173-180.

23. Lebre AT, Mendes MF, Tilbery CP, Almeida AL, Neto AS. Relação entre fadiga e distúrbios autonômicos na esclerose múltipla. Arq Neuropsiquiatr 2007;65:663-668.

24. Tilbery CP. Esclerose múltipla no Brasil: aspectos clínicos e terapêuticos. São Paulo: Atheneu, 2005:13-15.

25. Ferreira MLB, Machado MIM, Vilela ML, et al. Epidemiologia de 118 casos de esclerose múltipla com seguimento de 15 anos no Centro de Referência do Hospital da Restauração de Pernambuco. Arq Neuropsiquiatr 2004;62:1027-1032.

26. Morales RR, Morales NMO, Rocha FCG, Fenelon SB, Pinto RMC, Silva CHM. Qualidade de vida em portadores de esclerose múltipla. Arq Neuropsiquiatr 2007;65:454-460.

27. Miller DM, Rudick RA, Cutter G, Baier M, Fischer JS. Clinical significance of the multiple sclerosis functional composite: relationship to patient-reported quality of life. Arch Neurol 2000;57:1319-1324.

28. Benito-Leon J, Morales JM, Rivera-Navarro J. Health-related quality of life and its relationship to cognitive and emotional functioning in multiple sclerosis patients. Euro J Neurol 2002;9:497-502.

29. Pittion-Vouyovitch S, Debouverie M, Guillemin F, Vandenberghe N, Anxionnat R, Vespignani H. Fatigue in multiple sclerosis is related to disability, depression and quality of life. J Neurol Sci 2006;243:39-45.

30. Schulz KH, Gold SM, Witte J, et al. Impact of aerobic training on immune-endocrine parameters, neurotrophic factors, quality of life and coordinative function in multiple sclerosis. J Neurol Sci 2004;225:11-18. 